\title{
EXPanding ACCess to Engineering by Teaching Physics THROUGH BIOENGINEERING: STUDENT IDENTITY REFLECTIONS
}

\author{
Robyn Paul, Miriam Nightingale, Alina Ismaguilova, Laleh Behjat, Elena Di Martino and Qiao Sun \\ Schulich School of Engineering, University of Calgary \\ rmpaul@ucalgary.ca
}

\begin{abstract}
Diversity in engineering is a key goal, however a barrier for students from diverse backgrounds is the physics requirements in engineering. Often, they will have to choose between the three sciences, and don't realize that without physics, their options are limited. We launched a pilot program in 2019 to expand access into engineering. Students without high school physics can take a summer bridge program to teach them the fundamentals and prepare them for first year engineering. Physics is taught through bioengineering to leverage their biology background knowledge. This paper presents a thematic analysis of student reflections in the program, using student identity development as a framework.
\end{abstract}

Keywords: first-year engineering : summer bridge programs : bioengineering : high school physics : projectbased learning

\section{INTRODUCTION}

Diversity in engineering is a key goal for many universities. However, often the requirements to apply for engineering create a barrier for students from diverse backgrounds. Specifically, for most engineering schools across Canada, high school physics is an entrance requirement. Physics concepts and ways of thinking are foundational to engineering programs, so the requirement is sensible. However, students make the choice between the sciences (biology, chemistry, or physics) in grade 10, often without realizing the impact it will have on their postsecondary degree choices. For IB (International Baccalaureate) students specifically, they only have space in their timetable for two sciences and they must make a choice. Once students start applying to universities in their final year of high school, engineering programs are no longer an option due to missing physics pre-requisites. Furthermore, many students take physics before they have the math background, hence finding physics difficult to understand. For female students this feel can reinforce the social stereotypes of "females not being good at physics."

At the University of Calgary a pilot program was launched in 2019 to expand access into engineering, with a goal of increasing access to a wider talent pool. This paper will focus on a review of the program through student feedback received during the pilot year. Using a student identity development framework [10], we will better understand students' perspectives coming into the program.

Students who opted not to take physics in grade 10 oftentimes take other courses such as biology or chemistry instead. By teaching physics through bioengineering examples, we were able to leverage this background knowledge. Additionally, research shows that some excluded identities are more likely to persist in engineering when they understand how it can be applied to real world contexts [3].

The course content was developed in collaboration with our Continuing Education program. Logistically, they were able to support the running of the courses (as the pre-firstyear students are technically not yet university students). Additionally, they provided significant pedagogical support in developing the curriculum content. The main philosophy of the course was to learn physics through significant hands-on activities and labs, along with frequent guest speakers and field trips. There is a significant challenge of being able to teach high school physics in four weeks, however we strongly believe that learning with hands-on, project-based learning allows for deeper engagement with the content. We believe this approach helps to reinforce confidence and supports students in their transition to university.

Student feedback and reflections were collected during the program, as well as after their first semester of engineering. The reflections from the first two weeks in the program were analyzed with deductive thematic analysis [2] and qualitative coding [6], using student identity development as a framework [10]. The results from this research will be beneficial locally to understand how we can improve and expand the physics summer institute program. Nationally, this case study and research will help institutions understand how to design and implement programs that can continue working towards a more diverse engineering student population.

\section{LITERATURE BACKGROUND}

\subsection{Bridge programs}

Transition from high school to university can be challenging - both academically and socially. For this reason, many universities have offered "bridge" programs to support students through this transition. Many bridge programs are targeted to underrepresented students, to 
provide them with necessary supports during their transitional period.

Bridge programs have a few different purposes: they may either be an optional attendance, or a remedial academic requirement. The bioengineering institute program is the latter: it is a requirement for students who have not taken the high school physics courses. It is important to note that although bridge programs are often to raise the academic level of students, this is not the case for us. The students coming into our program are already academically competitive, they are just missing the physics requirement. They have conditional acceptance into engineering, and upon successful completion of the program, they are admitted into first-year university.

Although there is not much literature on physics bridge programs, there are many bridge programs which are targeted towards enhancing students' skills in mathematics $[5,11,17]$. These programs have shown that the format of a summer bridge program can shorten the mathematics gap, particularly for excluded identities in engineering.

Although the focus of most of these programs are academic achievement, it is important to consider the full picture of impact the program has [9]. For example, programs which target first-generation university students found that students in the bridge program were able to gain a strong sense of belonging [14], and improved academic self-efficacy, which is a positive predictor of first semester GPA [13].

Although the results from these studies are promising, there is also work showing that students' sense of belonging and professional identity increases during the bridge program, yet drops after the program [8]. Usually, summer bridge programs have much smaller class sizes and are slower paced, so although students can develop close relationships with the instructors and develop their professional identity during the program, afterwards they are still hit with the challenges of first year university courses.

It is still important to consider the many diverse reasons that students participate in summer bridge programs. For example, some students want to explore career options, others want to prepare for their classes, and some want to develop their non-academic skillsets [9]. Bridge programs also often provide students with an opportunity to reflect on their own learning, and gain self-awareness [9].

\subsection{Student identity development}

Engineering identity research has been studied for decades, but it was not until recently that the field has gained traction. In the Cambridge Handbook of Engineering Education, Tonso emphasizes that educators must first understand engineering identity in order to be able improve the learning environment for students [16]. For example, engineering identity has been connected to student retention, and the change of identity throughout a student's education plays a role in the student's persistence
[8]. If we can strengthen our educational approaches to foster stronger engineering identity development, we can support our students, particularly in their earlier years.

Many definitions of engineering identity have been proposed, although generally there is an understanding that engineering identity is tied to one's professional identity. Beam at al. define professional identity as "how closely an individual relates to a particular field, profession, or occupation" [1]. Other authors emphasize that professional identity is "double sided" and must consider both how someone identifies themselves, and how they are identified by others within their field [12]. In other words, there is both an individual and a social dimension of engineering identity (i.e. how one identifies with the profession and how one is identified based on the cultural norms of engineering [4]). This second part of identity emphasizes how it is not just about how we identify ourselves, but also how others perceive us and if the engineering culture recognizes us as being part of it [15].

Factors of engineering identity have also been studied. For example, engineering identity has been shown to be more conducive for students with access to peer networks and role models, male students, and students with extracurricular experience such as internships and informal learning activities [10]. Additionally, students with higher identity tend to have greater confidence in their math and science skills [10].

Overall, identity research has become important in recruiting and retaining minorities in engineering classrooms by creating more inclusive environments. After Morelock's 2017 review of over 40 articles on engineering identity, he had two main recommendations to educational practitioners: 1) exposure to new experiences is crucial in identity development and be sure to enhance these with reflections on how students connect with the activities personally; and 2) awareness of the barriers that minoritized students face in their engineering identity development process and ensure interventions are at minimum beneficial for these underrepresented students [10].

\section{CONTEXT: BIOENGINEERING SUMMER INSTITUTE (BSI)}

In 2019, University of Calgary created the bioengineering admissions route, providing students with the opportunity to apply to the program without high school level physics courses. The university now accepts biology courses in lieu of physics (all other requirements remain the same and all students are assessed using the same grade point average cut-off) provided that the incoming student completes the Bioengineering Summer Institute.

The Bioengineering Summer Institute is an intensive 4week course, with class 5 days per week and 6 hours of instruction per day. The course was designed to not only 
prepare students for the rigors of an engineering degree but also to present an alternative picture to traditional engineering as a career and discipline.

For assessment, we decided to eliminate letter grades to achieve better learning outcomes. We do so by making sure learning outcomes are thoughtfully and clearly defined. Lesson plans including lectures, learning activities, assignments, and projects clearly align and support the intended learning objectives. Self and group reflections at the end of a lesson are designed to support not only the grasp of important concepts but also the growth of student learning capacities. The intention behind this is to provide students with a deeper learning experience, that is focused on their learning rather than grades. Students assignments are reviewed and graded, and they are expected to complete all course requirements.

The physics and engineering principles taught in the course are explored through the lens of biology, biosystems, and biomedical applications drawing upon the students' existing knowledge and interests. For example, the students were first taught the concepts of work, pressure and flow through understanding the circulatory system and the work heart has to do to keep the blood flow. Then, when introducing the electrical components and their relationships in circuits, a parallel was made to the circulatory system in the human body. Current was synonymous with blood, voltage was represented by the blood pressure, and resistance was discussed as being a combination of several physiological factors such as blood viscosity and vessel diameter. The students were then tasked with designing an electric circuit analog of the system using breadboards. Another lesson involved the introduction of basic fluid mechanics and pressure-volume relationships by examining heart and cardiac cycle mechanics with the goal of designing an artificial heart prototype.

The program emphasized introducing the students to the engineering mindset and approach to problem solving. Students were encouraged to develop a versatile structured approach to problem solving and to determine relationships and principles themselves through critical thinking and inquiry. The majority of the course was taught through active learning techniques, with each physics concept illustrated through an experiment or design challenge. In one lesson, the students learned about the sport of Olympic luge, and subsequently designed their own "luge tracks" to learn about dynamic forces. Students needed to discover and utilise physical relationships such as the slider's acceleration, the incline of the track, and friction to build a track that a slider could safely complete in the fastest time. The relationship between centripetal force, track curve radius, and bank angle also had to be considered to ensure the slider stayed in the track through its entirety.

The scientific and engineering principles learned in the course are supplemented with guest speakers and facility tours showing the diversity of engineering applications beyond traditional roles. Speakers such as a medical resident in cardiac surgery talked to the students about the interdisciplinary nature between engineering and medicine, and the importance of engineers in his practice in developing surgical-assist devices. Another guest speaker was a professor from electrical engineering who talked to the class about electricity and the human body. There were also engineering students who were Olympic athletes and talked about how their sports and engineering are combines. Students are also given tours of research labs with focus areas such as bioprocessing techniques for large scale stem cell development and gait analysis.

\section{METHODOLOGY}

\subsection{Theoretical framework}

Within identity research, one can observe that there are some key aspects of engineering identity. Tonso uses figured worlds to better conceptualize identity, where she summarizes the characteristics to be: positionality hierarchy, social positioning, the importance of power in social interactions; space of authoring - how one integrates into the space / culture; and making of worlds - through our actions, we may shape the world we live in [15].

When summarizing Tonso's work, Dehing et al. summarize it well, where the process of identity development involves: meeting the requirements of the social role, which includes both acting as an engineer and others recognizing them as being an engineer; and identifying and believing themselves to be an engineer [4].

There are similarities between these framings of engineering identity, where one can see both the social role (internal and external), and the personal belief in oneself. For the purpose of this research, we used Morelock's summary of these identity statements as our theoretical framework in the analysis [10]:

- acting like an engineer,

- being recognized as an engineer, and

- believing oneself to be an engineer.

\subsection{Data sources}

The data analyzed included three assignments that were part of the class requirements. This research was approved by the CFREB (Conjoint Faculties Research Ethics Board). Of the 12 students contacted, four students consented for their data to be included in the research.

The first one was the Day 1 Self Reflection that asked questions about students' expectations for the course, their confidence in physics, and their feelings towards physics.

The second assignment asked students about their first week of the BSI, Self Reflection A: Reflect on your first week. This assignment included five open-ended questions, and six questions that asked students to "complete the following sentences". The open-ended questions asked the student to state their most memorable part of the week, 
feelings about classroom involvement, what they had learned so far, and how they might use this learning going forward. The finish-the-sentence questions included what surprised them, pleased them, disappointed them, what they already knew, and the different ways they are most and least successful as a learner.

The final assignment used was a reflection at the end of the second week (of the four-week program). The reflection asked students to imagine themselves walking across the stage in five years to get their degree and consider their biggest strengths and how they helped them get there. There was also a question on why they chose to pursue engineering, and why they may have chosen to not take physics 20 and/or 30 in high school.

The assignments from the four consenting students were anonymized and given a participant code before any qualitative analysis was conducted. The research ethics consent specifically explains the small size of the class, and the possibility of students not remaining anonymous to the researchers due to the ability of the researchers possibly being able to recognize their handwriting, or recognize the specific stories being told.

\subsection{Qualitative data analysis}

The reflections from the first two weeks in the program were analyzed with deductive thematic analysis [2] using student identity development as a theoretical framework [10]. We followed Braun and Clarke's method for thematic analysis, which they describe as "a method for identifying, analyzing and reporting patterns within data" [2].

Through qualitative coding [6], we used a systematic process to code the data, and continuously check the codes for accuracy within their themes. The approach to the analysis was routed in constructionism, where the experiences and knowledges are socially constructed. Specifically, within the bioengineering program, we wanted to better understand how students constructed their engineering identity.

We followed the steps of thematic analysis, as laid out by Braun and Clarke [2]: familiarize ourselves with data; generate initiate codes; search for themes; review themes; define and name themes; and producing the report. As we were using deductive thematic analysis, while we were coding, we grouped the codes within our theoretical framework.

\section{RESULTS}

The assignments were coded based on the three components of the theoretical framework. Eleven themes emerged from the analysis, ten of which fit within the framework (see Table 1). The sections below describe each themes with relevant quotes from the student assignments.

\subsection{Acting like an engineer}

The four themes under acting like an engineer really focus on the skillsets and mindsets required for engineering. As they are just going into university, some of these themes more closely relate to acting like an engineering student where the students feel they are connecting with the identity of being a university student. Additionally, students spoke about their future career aspirations, which connected closely with their professional engineering identity.

Table 1: Mapping of observed themes to identity framework

\begin{tabular}{|l|l|}
\hline Identity Framework & Themes \\
\hline $\begin{array}{l}\text { Acting like an } \\
\text { engineer }\end{array}$ & $\begin{array}{l}\text { 1. Being challenged } \\
\text { 2. Skill development } \\
\text { 3. Applications to real world } \\
\text { 4. Future career considerations }\end{array}$ \\
\hline $\begin{array}{l}\text { Being recognized as } \\
\text { an engineer }\end{array}$ & $\begin{array}{l}\text { 5. Supportive classroom } \\
\text { 6. Contributing to learning } \\
\text { environment } \\
\text { 7. Previous learning experiences }\end{array}$ \\
\hline $\begin{array}{l}\text { Believing oneself to } \\
\text { be an engineer }\end{array}$ & $\begin{array}{l}\text { 8. Pride of overcoming challenge } \\
\text { 9. Passion and joy for learning } \\
\text { 10. Confidence in oneself }\end{array}$ \\
\hline Other & $\begin{array}{l}\text { 11. Getting a refresher and step- } \\
\text { up for first year }\end{array}$ \\
\hline
\end{tabular}

5.1.1. Theme 1. Being challenged. Many students felt that the challenging problems were part of being an engineering student, and they felt problem solving was an introduction to what it would be like to be a university student. One student said, "I enjoy the complexity of what we are learning, and it is very exciting to see that we are seeing examples from first-year courses!" Another student felt they were being challenged more than they had before, they said "the lab was challenging and the math I had to do was unlike anything I had ever learned before."

There were also some students who saw this challenge as part of their identity of becoming an engineer. Students talked about the "challenge" of engineering and how this would lead to a "fulfilling degree."

Although some students really leaned into the identity of engineering being challenging, other students were resistant and did not enjoy certain aspects of challenging problem solving. For example, one student said, "I was confused about how to get a foundational understanding of the topics," another disliked "how convoluted certain aspects are".

5.1.2. Theme 2. Skill development. Throughout their reflections, students mentioned the different skills they were developing that were helping them to act more like an engineer. One student said that the program helped them to practice "problem solving and learning how my "mind of an engineer' might differ from others in group projects and activities." Some students observed how they worked on 
engineering teams, where they said, "I enjoy collaborating [and] collective problem solving."

Others talked about specific skills that were helping them to act more like an engineering student, like improving their study habits and note taking, developing a strong "work ethics," and learning to "ask questions to further understanding."

5.1.3. Theme 3. Application to real world. Students felt what they were learning was really allowing them to understand what it meant to be an engineer in the real world. One student said "The part of physics I enjoy are to do with astronomy + the biology aspects, because its more understandable (and more fun)." Within this program specifically, a lot of students appreciated the connection to biology and bioengineering applications: "I wanted to be a doctor, but I found after learning about this bioengineering course that I can do so with engineering."

Other students discussed how this application to the real world was why they wanted to be an engineer. Physics (and engineering) to them allows them to be like an engineering because "it helps me to make sense of the world."

A sub-theme within this theme was an emphasis on the hands-on learning. Students really felt through the labs they were really acting like an engineer through the handson learning activities. For example, one student said, "The luge activity was very engaging and fun given it was a lab that required both critical thinking, design, and trial and error." Another student said, "I like labs and demos because I find that they make it easier to understand topics."

Theme 4. Future career considerations. The final theme within acting like an engineer was where students considered their future career, and how they were not only becoming an engineering student but thinking about what kind of engineer they wanted to become. For example, one student said they saw engineering as "an outlet to an extensive range of careers, ideas, and knowledge." Another student said, "Engineering is broad but also specific, you can do so much and impact the people around you in such a positive manner!" Many students didn't know what they specifically wanted to do, but they knew that with engineering there would be options, "I felt like there was some clarity in what I could do after 4 years."

Students also felt that the bioengineering institute was an opportunity to learn about career options, where they could "learn more about the different areas of engineering" they hoped that this course would help "figure out which type of engineering I want to do." These quotes show how the students wanted to act like different types of engineers to explore what type of engineer they might want to be.

\subsection{Being recognized as an engineer}

Within the identity framework, being recognized as an engineer is about how the external world perceives and accepts you. Theme 5 and 6 describe the positive influence of the bioengineering institute on supporting students feel like they are part of a learning environment, whereas Theme 7 demonstrates how significant a negative impact can have on students if they do not feel safe in their learning environment.

5.2.1. Theme 5. Supportive classroom. Through student feedback and reflections, it is evident that the design of the BSI was conducive to learning, and the instructors actively fostered a safe space for learning. For example, one student said, "I really enjoy coming here and learning about physics in a comfortable learning environment, where I'm not pressured and can learn ideas at my own pace." The instructors were also described to be "approachable" and "helpful," and the "atmosphere is welcoming." These descriptions really emphasize that the students felt they were recognized as engineering students and felt supported in their learning.

Although students were graded and given feedback on their work, the design of the institute was designed without any final grades or minimum grades at the end. This learning approach helped students to explore the topic based on their own interests without needed external motivations. One student really highlighted this by saying, "the marking structure is not in a place to fail you but help you learn."

\subsubsection{Theme 6. Contributing to learning environment.} Another way that students felt recognized as engineering students is that they were encouraged to actively participate and that it was "inviting". One student said, "I feel really involved in group work as well as in the class, I feel like I can ask anyone for help, and I'll get it." Another student appreciated that they were recognized as individual learners, "I love the learning environment, and I greatly appreciate I can ask questions whenever I am confused."

A few students believe that this learning environment contrasted with what they were expecting in their first year of engineering, where engineering is a "degree known for its difficulty and high competition". Although they felt the individual recognition in the BSI, they were preparing themselves to be less recognized as engineers when they stepped into classes of more than 200.

5.2.3. Theme 7. Previous learning experiences. When reflecting on why they didn't take physics previously, both in their reflections and during multiple in-class conversations, students mentioned previous negative experiences. One student said, "I've had a lot of bad physics teachers that make me nervous to embrace the subject." It is evident that these prior teachers made them feel like they could not be good at physics, which affected their belief of being able to be an engineer. 


\subsection{Believing oneself to be an engineer}

The last characteristic of the identity framework is believing oneself to be an engineer. This is a critical component of one's engineering identity, even if our students act as an engineer and are recognized as one, they must believe they are an engineer in order to develop their professional engineering identity. The three themes here highlight ways in which they did and didn't believe in themselves as an engineer.

5.3.1. Theme 8. Pride of overcoming challenge. Theme 1 talked about how students felt they were acting as an engineer when they were challenged. This theme highlights how when students were able to overcome those challenges, they were proud, and they believed in themselves. For example, one student said that they were "surprised I was able to absorb the information well" and that it stood out for them that "I can actually understand physics if I pace myself."

A sub-theme within Theme 8 is around the students' resiliency, and their pride in their ability to persist. A few informal classroom discussions on this topic also really highlighted that the students knew the difficulty ahead of them, but felt their resiliency would be what helped them through. When thinking of their graduation day in 5 years, they said "I will be proud of how far I have come and my ambition that has brought me to this point." Another student said, "The biggest strength that would help me in succeeding in engineering would have been not giving up."

5.3.2. Theme 9. Passion and joy for learning. The BSI was able to foster a safe learning environment where students could believe in themselves and explore their joy of learning. When talking about one of their labs, one student said they enjoyed being able to "convert out "piece of art' into mathematical equations!"

Some students had a passion for striving to be their best, where they said they "I feel a strong urge to master this topic, I plan to do so by going back and rewriting/ reviewing my notes to help me understand the topic." This shows they believed in themselves as an engineer, and they could use their passion to learn to become an even better engineer. Others were excited about the prospects of learning and innovating, "there is a lot undiscovered". Some students were inspired from their family members, "I like building things and my grandpa did engineering and my mom used to tell me stories about the cool stuff he did."

5.3.3. Theme 10. Confidence in oneself. Through the reflections we saw students' confidence in themselves, or lack of confidence in themselves as engineers, often is reflected through the lens of their perceived physics problem-solving abilities.

Some students were confident, with one student stating that they felt "physics is not difficult once you get a good grasp of theory. They described how they felt they succeeded in learning when they "could combine skills from math, physics \& logic to solve a tough problem."

Some students felt less confident with their problem solving: "I do not feel fully confident in my abilities to problem solve in unconventional situations". One student felt confident about their social skills, but followed this up by saying they hope to use their social skills as an advantage and it is "why I think I'd be good at [engineering] even though I'm not the smartest."

Students who have had negative experiences with physics teachers in the past described their lack of confidence as anxiety towards the subject. One student said, "It is not that I can't do the problems, it's that I feel so anxious while doing the problems that I can't think properly..." We see here again how the lack of positive role models has left these students not believing in their ability to become an engineer.

\subsection{Other}

5.4.1. Theme 11. Getting a refresher and step-up for first year. The final theme was the only one that did not fit within the identity framework, as it is specifically towards the intent of the BSI. The bridge program providing an opportunity for students to refresh themselves on physics principles, and they also hoped it would give them a stepup in their first year of engineering. For example, one student said, "I would like this month to be an opportunity to learn the 'tricks' and hard stuff I'm going to struggle with in first year." Another student said they want to learn "new skills and a change to refresh the thinks I have forgotten," whereas another talked about the desire to be "prepared for University." Underlying these quotes, it is evident that the students had a strong desire to be successful in engineering.

\section{CONCLUSION}

Through this work, we have gained insight into the engineering identity of students who went through a bioengineering physics program for expanded access into engineering. We found that engineering identity is about challenge and overcoming challenge, through theme 1 (being challenged) and theme 8 (pride and joy for learning). We also found that the transition for students into university brought up some fear and anxieties. This was shown in theme 10 (confidence in oneself) and theme 11 (getting a refresher and step-up for first year). Students really wanted all the extra support they could get in order to help them succeed as they moved through this big transitional period in their life.

Lastly, through the students' reflections we can really see the impact that mentors and others have on identity development. This can be positive, such as theme 5 (supportive classroom) which really showed how the BSI instructors fostered a safe space for learning; and it can also be negative, where theme 7 (previous learning experiences) 
showed how lack of a supportive learning environment could create anxiety for students. Theme 10 (confidence in oneself) also highlighted how confidence can be influenced by others and by the learning environment we foster for our students.

\subsection{Next Steps}

As the first cohort of students is going through their first year, we are excited to follow-up with these students to better understand the impact of the program. We would like to understand if the program was successful and if the students were academically successful in their first year, particularly in the courses which require high school physics as a prerequisite.

We would also like to investigate our approach to the curriculum design for teaching physics. For example, how did teaching physics in the context of biology help students with confidence? This would help us to better understand if our approach was beneficial for our target market (i.e. students who had taken grade 12 biology).

\section{Acknowledgements}

We would like to acknowledge the support of the Continuing Education faculty in the development of the curriculum for BSI. We would also like to acknowledge the Schulich School of Engineering's financial support for a research assistantship to investigate the program impact and outcomes. Additionally, Dr. Bill Rosehart, current Dean of our engineering faculty, was the proponent and architect behind the program. We appreciate his trust in us to implement the project. Both Bill and Anders Nygren from the engineering dean's office have been incredibly involved in the development, delivery, and implementation of the BSI, and we appreciate their support.

\section{References}

[1] Beam, T. K., Pierrakos, O., Constantz, J., Johri, A., \& Anderson, R. (2009). Preliminary findings on freshmen engineering students' professional identity: Implications for recruitment and retention. In American Society for Engineering Education. American Society for Engineering Education.

[2] Braun, V., \& Clarke, V. (2006). Using thematic analysis in psychology. Qualitative research in psychology, 3(2), 77-101

[3] Davis, C. S. G., \& Finelli, C. J. (2007). Diversity and retention in engineering. New Directions for Teaching and Learning, 2007(111), 63-71.
[4] Dehing, F., Jochems, W., \& Baartman, L. (2013). Development of an engineering identity in the engineering curriculum in Dutch higher education: an exploratory study from the teaching staff perspective. European Journal of Engineering Education, 38(1), $1-10$.

[5] Doerr, H. M., Ärlebäck, J. B., \& Costello Staniec, A. (2014). Design and effectiveness of modeling-based mathematics in a summer bridge program. Journal of Engineering Education, 103(1), 92-114.

[6] Elo, S., \& Kyngäs, H. (2008). The qualitative content analysis process. Journal of Advanced Nursing, 62(1), 107-115.

[7] Kirn, A., Godwin, A., Benson, L., Potvin, G., Doyle, J., Boone, H., \& Verdin, D. (2016). "Intersectionality of Non-normative Identities in the Cultures of Engineering" in Proceedings of ASEE Annual Conference \& Exposition.

[8] Knight 2013

[9] Lee, W. C., Wade, C. S., \& Amelink, C. T. (2014). Examining the transition to engineering: A multi-case study of six diverse summer bridge program participants. In 121st ASEE Annual Conference \& Exposition.

[10] Morelock, J. R. (2017). A systematic literature review of engineering identity: definitions, factors, and interventions affecting development, and means of measurement. European journal of engineering education, 42(6), 1240-1262.

[11] Nite, S. B. (2012). Bridging secondary mathematics to postsecondary calculus: A summer bridge program. Texas A\&M University.

[12] Stevens, R., O'connor, K., Garrison, L., Jocuns, A., \& Amos, D. M. (2008). Becoming an engineer: Toward a three dimensional view of engineering learning. Journal of Engineering Education, 97(3), 355-368.

[13] Strayhorn, T. L. (2011). Bridging the pipeline: Increasing underrepresented students' preparation for college through a summer bridge program. American Behavioral Scientist, 55(2), 142-159.

[14] Tomasko, D. L., Ridgway, J. S., Waller, R. J., \& Olesik, S. V. (2016). Association of summer bridge program outcomes with STEM retention of targeted demographic groups. Journal of College Science Teaching, 45(4), 90.

[15] Tonso, K. L. (2006). Student engineers and engineer identity: Campus engineer identities as figured world. Cultural studies of science education, 1(2), 273-307.

[16] Tonso, K. L. (2014). Engineering Identity. Chapter 14 in Cambridge Handbook of Engineering Education Research, 267282.

[17] Zhou, Y., Islam, N., Pan, C. C. S., \& Kumar, S. (2014, November). Shorten the Math Gap for Pre-Engineering Students With Intensive Summer Bridge Program. In ASME 2014 International Mechanical Engineering Congress and Exposition. American Society of Mechanical Engineers Digital Collection. 